\title{
El Estatuto del personal de las asambleas legislati- vas autonómicas, como reserva competencial en el ordenamiento jurídico derivado parlamentario
}

Rafael Cano Silva

Doctor en Derecho Administrativo. Funcionario del Cuerpo Técnico

del Parlamento de Andalucía

SUMARIO:

I. INTRODUCGIÓN. II. LA RESERVA DE LAS GÁMARAS. 1. Contenido que constituye la materia reservada de los estatutos del personal. 2. Reserva constitucional. Del Estatuto del Personal de las Cortes Generales. 3. Reserva estatutaria. Del estatuto del personal de las asambleas legislativas de las comunidades autónomas. III. LA RESERVA DEL ESTATUTO DEL PERSONAL GOMO GOMPETENGIA EXCLUSIVA Y ESPECÍFICA DE LOS PARLAMENTOS AUTONÓMICOS. 1. Competencia establecida en el Estatuto de Autonomía respectivo. 2. Competencia establecida fuera del Estatuto de Autonomía respectivo. 3. Conclusión. IV. CONCLUSIONES: REFLEXIÓN EN TORNO A LAS CITADAS RESERVAS Y SU RELACIÓN CON LA AUTONOMÍA PARLAMENTARIA. V. BIBLIOGRAFÍA

RESUMEN. La Constitución Española y los diversos Estatutos de Autonomía de las comunidades autónomas realizan una reserva a favor de sus parlamentos, al objeto de la organización interna, si bien no todos lo hacen en materia de personal. Este artículo muestra como esa reserva estatutaria debe ser considerada como competencia exclusiva de la comunidad autónoma y como competencia específica de su cámara parlamentaria, al objeto de la determinación de los estatutos del personal de las asambleas legislativas en el sistema de fuentes del ordenamiento jurídico español, erigiéndose el sistema de distribución competencial en un prius en la fijación del tipo normativo, al objeto de que los mismos puedan tener rango y fuerza de ley.

PALABRAS CLAVE: Competencias autonómicas, estatutos del personal, Función Pública, parlamentos autonómicos.

ABSTRACT: The Spanish Constitution and the various Statutes of Autonomy of the Autonomous Communities make a reservation in favor of their Parliaments for the purpose of internal organization, although not all do so in terms of staff. This article shows how that statutory reserve should be considered as the exclusive power of 
the Autonomous Community and as a specific power of its Parliamentary Chamber for the purpose of determining the Statutes of the staff of the Legislative Assemblies in the system of sources of the Spanish legal system, establishing itself the distribution system of power in a "prius" in the setting of the normative type, in order that they may have the rank and force of law

KEYWORDS: Autonomic powers, Statutes of the staff, civil service, autonomic parliaments.

\section{INTRODUCGIÓN}

En líneas generales, los estatutos del personal de los parlamentos autonómicos (en adelante, EE.PP.), se han asimilado a otros estatutos de organización en materia de personal, como es el caso, por ejemplo, del Consejo General del Poder Judicial, u otros órganos con mayor o menor grado de autonomía respecto a la regulación del personal que presta sus servicios en los mismos.

No obstante, únicamente una pequeña parte de la doctrina jurídica prioriza y diferencia los aprobados por las asambleas parlamentarias en relación con los demás órganos carentes de potestad legislativa; a estos efectos, RAFAEL CANO dice:

"Pero esa capacidad no es la misma que la reconocida a otras instituciones como la Administración autonómica, entes locales o universidades, sino que es una competencia normativa que aprueba el propio parlamento; el poder público sobre el que descansa la competencia legislativa, de ahi que, en muchos casos, esta capacidad normativa se traduzca en capacidad legislativa para la regulación de su propio personal."

Y, aún es más pequeño el número de aquellos autores que ponen el rasgo diferenciador en la distribución competencial que ostenta el órgano para elaborar y aprobar estos estatutos. En tal sentido, el autor citado continúa diciendo:

"En consecuencia, vemos la importancia que adquiere el hecho de que estos parlamentos autonómicos ostenten la facultad normativa para aprobar sus EE.PP. con rango de ley, pues es, precisamente el rango legal de dicha norma la que establecerá de forma rotunda su "independencia" respecto a determinados ámbitos normativos estatales y competenciales como se recogen en las conclusiones de este estudio."2

Consecuentemente con todo lo expuesto anteriormente, en este artículo se analizará brevemente la necesidad de atribución de competencias por parte de los diversos Estatutos de Autonomía (en adelante, EE.AA.) a favor de sus cámaras par-

1 CANO SILVA, R., "La potestad autonormativa en relación con los estatutos del personal de los parlamentos autonómicos". en Revista de Estudios de la Administración Localy Autonómica, núm. 9 (2018), p.102.

$2 \quad$ Ibidem p. 103. 
lamentarias respecto a los EE.PP., ya que desde nuestro punto de vista, el sistema de distribución competencial se convierte en un prius en la fijación del tipo normativo de esta tipología de norma, de tal manera que será conditio sine qua non para que los mismos puedan tener rango y fuerza de ley, siempre y cuando cumplan otros requisitos.

No obstante lo anterior, no es objeto de este artículo el estudio individualizado de cada uno de los EE.AA. de las comunidades autónomas (en adelante, CG.AA.), ni de sus respectivos EE.PP., sino el mecanismo o engranaje necesario que forma parte del ordenamiento jurídico al objeto de dotar de un contenido pleno a los diversos EE.PP. como norma administrativa parlamentaria, así como la determinación de su rango normativo.

\section{LA RESERVA DE LAS CÁMARAS}

La doctrina jurídica es unánime al afirmar, respecto a los reglamentos parlamentarios, que es incongruente en la actualidad ubicar este tipo de normas en la escala jerárquica de las normas del ordenamiento jurídico general, puesto que lo que hay es una separación de competencias constitucionalmente garantizadas. ${ }^{3}$

De modo análogo, prima facie, podríamos afirmar lo mismo respecto a los EE. PP., tanto si nos referimos al Estatuto del Personal de las Cortes Generales (en adelante, EPCG), como a los de los diferentes parlamentos autonómicos, si bien ello hay que matizarlo, puesto que, a pesar de que juega el principio de competencia, para lo cual deberemos atender al sistema de distribución de las mismas entre Estado-CC. AA., también hay que observar los límites establecidos por el ordenamiento jurídico al principio de reserva competencial.

La Constitución atribuye, a través de su art. 72, al EPGG la regulación del personal que presta sus servicios en las Cortes Generales. De modo análogo, algunos EE.AA. hacen lo propio respecto a su personal, encomendando su regulación a sus respectivos EE.PP. En consecuencia, se están realizando unas reservas a dichos EE. PP. como únicas normas legitimadas para llevar a cabo tal regulación y, por ende, impidiendo que otras normas ejerzan una intromisión reguladora en dicho ámbito. Debido a ello, se les puede imputar a los EE.PP., desde este punto de vista, el carácter de norma primaria y directamente derivada de la Constitución y/o de los EE.AA., en su caso.

A mayor abundamiento de lo anterior, podemos decir que la reserva competencial a favor de las asambleas legislativas que se hace a favor de los EE.PP. (la Constitución, en el caso del EPCG, y los EE.AA. en el caso de los restantes EE.PP.) es una

3 MARTÍNEZ-ELIPE, L., "Fuentes del Derecho y del ordenamiento jurídico parlamentario", en I fornadas de Derecho Parlamentario, vol. II. Madrid, Congreso de los Diputados, 1984, p. 458. 
cuestión implícita de su condición de norma primaria e incardinada directamente en la Constitución (o en su caso, en los EE.AA.) ${ }^{4}$

En el sentido expuesto en el párrafo anterior, PUNSET BLANCO, refiriéndose a los reglamentos parlamentarios (y que nosotros aplicamos a los EE.PP. en tanto que comparten la misma casuística, es decir, la reserva competencial), indica que

"[...] la no subordinación de los reglamentos parlamentarios a otra norma que la Constitución o los Estatutos de Autonomía [...] es el correlato de la atribución a la potestad reglamentaria de un espacio exclusivo de regulación. $Y$ viceversa; si la reserva ha de considerarse instituida por la Constitución o los Estatutos, entonces los reglamentos han de reputarse de normas primarias $" 5$.

De tal modo, de la reserva a favor de los EE.PP.,

"no se deduce, sin embargo, superioridad formal alguna de los Rreglamentos parlamentarios frente a la eventual norma invasora, sino, simplemente, inferioridad de esta última respecto a la Constitución, que es quien ha establecido la reserva" ${ }^{\text {. }}$.

En definitiva, a los efectos de los EE.PP., la cuestión no es tan simple como sucede con otras normas de las asambleas legislativas, como los reglamentos parlamentarios. En consecuencia, deberemos, pues, tener en cuenta:

1.- Si la elaboración y aprobación de los EE.PP. constituyen una competencia de la respectiva comunidad autónoma por así recogerlo el respectivo Estatuto de Autonomía.

2.- Si tal competencia es atribuida de forma específica a su asamblea legislativa o es regulada en materia de Función Pública, conjuntamente con la realizada para la Administración pública autonómica.

3.- Tanto si es competencia exclusiva de la comunidad autónoma, como si no, y/o específica de su cámara parlamentaria, si le es de aplicación el Real Decreto Legislativo 5/2015, de 30 de octubre, por el que se aprueba el Texto Refundido de la Ley del Estatuto Básico del Empleado Público (en adelante, EBEP), de conformidad

4 Respecto a la primariedad de los EE.PP. de las cámaras parlamentarias, la actual jurisprudencia exige que haya una conexión o vinculación directa con el Estatuto de Autonomía respectivo (sin perjuicio, además, de que los citados EE.PP. de las asambleas legislativas sean aprobados por un órgano parlamentario con competencia legislativa). Por tanto, observamos cómo primariedad y reserva son aspectos relacionados que se constituyen como presupuestos mutuos.

5 PUNSET BLANCO, R., "La posición de los reglamentos parlamentarios en el ordenamiento español" en J. C. DA SILVA OCHOA (coord.), Las fuentes del Derecho parlamentario, Vitoria-Gasteiz: Parlamento Vasco, 1996, pág. 75.

6 PUnSET BLANCO, R., Las Cortes Generales. Madrid, Centro de Estudios Constitucionales, 1983, pág. 93. Si bien insistimos que el autor se está refiriendo a la reserva a favor del reglamento parlamentario que hace la Constitución Española. 
con su normativa interna (potestad que confiere el art. 4.a) del EBEP a las asambleas legislativas de las CC.AA. para su aplicación, si así lo dispone su legislación específica).

4.- Consecuencia de lo anterior, en tales supuestos, le será aplicable la normativa básica estatal, es decir, en aquellos casos en los cuales la legislación específica de las asambleas legislativas disponga que se aplique directamente el EBEP.

5.- En cualquier caso, y sin perjuicio de lo anterior, los EE.PP. tendrán la limitación de determinados preceptos constitucionales y estatutarios, así como los que se desprendan de los tratados internacionales y del derecho de la UE.

Respecto a toda esta reserva "matizada", constituye premisa básica inicial determinar qué materias han de constituir esa materia reservada a los EE.PP., es decir, cuál es su contenido.

\section{Contenido que constituye la materia reservada de los EE.PP.}

Sin perjuicio del carácter legal o reglamentario de los EE.PP. de las asambleas legislativas, resultando que los mismos constituyen objeto de reserva en algunos casos por los respectivos EE.AA. (de modo análogo a como lo hace el EPCG respecto de la Constitución), y en cualquier caso son objeto natural de regulación por las propias cámaras parlamentarias (con independencia de que estén previstos o no por dichos EE.AA.), es evidente la importancia del ámbito material que deben regular, es decir, de su contenido.

Parece evidente el paralelismo existente entre los EE.PP. de las cámaras autonómicas y el estatuto de los funcionarios públicos de la Administración pública. Mientras que los primeros tienen por objeto la regulación del personal al servicio de dichas asambleas, los segundos tienen por objeto la regulación del personal al servicio de dichas Administraciones públicas. En otras palabras, y tal como dice PUNSET BLANCO ${ }^{7}$, la propia denominación refleja fehacientemente la materia que ha de abordar. Y es que el art. 103.3 de la Constitución Española (en adelante, $\mathrm{CE}$ ), al referirse a la reserva de ley a la que queda sujeto el Estatuto de los Funcionarios Públicos de la Administración Pública, está contemplando el acceso a la Función Pública (de acuerdo con los principios de mérito y capacidad), el derecho a sindicación, el sistema de incompatibilidades y las garantías para la imparcialidad en el ejercicio de sus funciones. En tal sentido, los reglamentos parlamentarios, tanto

7 PUNSET BLANCO, R. (1996: 76). 
de las Cortes Generales como del resto de los parlamentos autonómicos, se refieren en términos análogos ${ }^{8}$.

La sentencia del Tribunal Constitucional (en adelante, STG) 99/1987, de 11 de junio, ${ }^{9}$ establece que la CE reserva "[...] a la ley la regulación de la situación personal de los funcionarios públicos [...]”. La citada STG aclara los contornos que comprenden la "situación personal de los funcionarios", y que son, entre otros, "la adquisición y pérdida de la condición de funcionario, promoción en la carrera administrativa, situación, derechos y deberes, y responsabilidades de los funcionarios y a su régimen disciplinario, asi como a la creación e integración, en su caso, de cuerpos y escalas funcionariales y al modo de provisión de puestos de trabajo [...]" y añade: "descartándose, de este modo, todo apoderamiento explícito o implícito a la potestad reglamentaria para sustituir a la norma de ley en la labor que la Constitución le encomienda".

8 De tal modo, la Disposición Final Cuarta del Reglamento del Congreso de los Diputados establece que "los derechos, deberes, situaciones, funciones y competencias de los funcionarios al servicio del Congreso serán los determinados en el Estatuto de Personal de las Cortes Generales". La Disposición Adicional Tercera del Reglamento del Senado contiene el mismo texto, pero referido a los funcionarios del Senado.

De análogo modo son los términos que recogen varios reglamentos parlamentarios: La Disposición Adicional Segunda del Parlamento de Andalucía establece los términos "derechos, deberes y situaciones del personal", el art. 71.1 del Parlamento de Canarias se refiere al "régimen del personal, derechos, obligaciones, régimen retributivo; los arts. 57.2 y 72 del Reglamento del Parlamento del País Vasco disponen que el estatuto del personal de dicho parlamento regulará "los derechos, deberes, situaciones y funciones"; la Disposición Final Primera del Reglamento del Parlamento de Cantabria; la Disposición Final Tercera del Reglamento de las Cortes de Castilla y León; la Disposición Adicional Cuarta del Parlamento de Galicia, y la Disposición Adicional Tercera, en su párrafo $1^{\circ}$, del Parlamento de Navarra establecen los términos "derechos, deberes, situaciones, funciones y competencias"; el art. 72 del Reglamento de las Cortes de Castilla-La Mancha "[...] la forma de ingreso y el régimen de personal". En definitiva, diversos modos de enunciar el contenido, que es mimético del referido por la Constitución para los funcionarios de la Administración pública.

No obstante lo anterior, existen reglamentos parlamentarios que, a pesar de hacer referencia a un estatuto del personal, no establecen su contenido; así sucede con el art. 166 del Reglamento del Parlamento de Asturias, el art. 63.2 del Reglamento de las Islas Baleares, el art. 78.3 y la Disposición Transitoria Segunda de la Asamblea Regional de Murcia, el art. 164 del Reglamento del Parlamento de La Rioja, el art. 110 del Reglamento de las Cortes Valencianas. O bien son más laxos, como hace el art. 200.3 del Reglamento del Parlamento de Cataluña, el art. 87 del Reglamento de la Asamblea de Madrid o el art. 117.1 del Reglamento del Parlamento de Extremadura al enunciar que el estatuto del personal regulará el régimen jurídico del personal a su servicio, pero sin precisar nada más.

Por último, existe un reglamento que ni siquiera hace alusión al estatuto del personal a su servicio. Tal es el caso de las Cortes de Aragón.

9 Consecuencia del recurso de inconstitucionalidad 763-1984, promovido por 54 diputados del Congreso contra determinados preceptos de la Ley 30/1984, de 2 de agosto, de Medidas para la Reforma de la Función Pública. 
En consecuencia, los EE.PP. de las asambleas legislativas, al igual que hace el EPCG, desarrollan dichos contenidos a través de sus textos, siendo la mayoría de las reformas de los mismos meras adaptaciones a novedades legislativas introducidas en la legislación que regula a los funcionarios de las administraciones públicas, tal como apunta GARCÍA-ESCUDERO ${ }^{10}$. Estas adaptaciones o regulaciones estatutarias podrán ser mediante remisiones a otras fuentes normativas o de propia creación, como ya vimos. De hecho, el propio art. 39.4 del EPCG establece que "el ejercicio por los funcionarios de las Cortes Generales de los derechos de sindicación, representación, participación, negociación colectiva y huelga se inspirará en los criterios de la regulación establecida por la ley para los funcionarios públicos. Las Mesas del Congreso de los Diputados y del Senado, en sesión conjunta, adaptarán dicho régimen al ámbito de la Administración parlamentaria”; adaptación que ha sido objeto de recurso de amparo núm. 442/95, contra la Resolución de los presidentes del Congreso de los Diputados y del Senado, de 20 de mayo de 1988, por la que se dictan normas reguladoras de las elecciones a la Junta de Personal de las Cortes, estableciendo la STC 121/1997, de 1 de julio, FJ 10" que "la autonomía organizativa de las cámaras (art. 72.1 C.E.) no cobija una potestad normadora de carácter genérico [...]", por lo que deberá limitarse a otras disposiciones normativas, si bien permitiéndole una modulación y adaptación de esas previsiones normativas.

Mención específica merece el régimen de incompatibilidades de los funcionarios parlamentarios, pues si a lo largo de este artículo siempre hemos ido haciendo un paralelismo entre el EPCG y los diversos EE.PP. de las asambleas legislativas de las CG.AA., no ocurre lo mismo en el régimen de incompatibilidades. De hecho, así lo constata la regulación que hace la Ley 53/1984, de 26 de diciembre, de Incompatibilidades del Personal de las Administraciones Públicas, cuyo art. 2 no contempla en su ámbito de aplicación al personal al servicio de las Cortes Generales, estableciendo la Disposición Final Segunda que "el régimen de incompatibilidades del personal de las Cortes Generales se regulará por el estatuto al que se refiere el articulo 72.1 de la Constitución, que se ajustará a la presente ley". Sin embargo, el citado art. 2, en su apartado 1.b), incluye en el ámbito de aplicación al "personal al servicio de las administraciones de las comunidades Autónomas y de los organismos de ellas dependientes, así como de sus asambleas legislativas y órganos institucionales". Todo ello sin perjuicio de que pueda pensarse que sea lo más adecuado o no que dicha regulación sea realizada básicamente por una ley en vez de por el EPCG ${ }^{11}$, pues no podemos obviar la innumerable legislación a la que están sujetas tanto las Cortes Generales como los parlamentos autonómicos, como sucede en materia de autonomía organizativa y administrativa con las leyes de transparencia o

10 GARCÍA-ESCUDERO MÁRQUEZ, P., "Artículo 72.1: autonomía funcional de las cámaras: reglamentaria, presupuestaria y de personal", en O. ALZAGA VILLAAMIL (dir). Comentarios a la Constitución Española, Vol. VI, Madrid, Cortes Generales, Edersa, 1998, p. 426.

11 GARCÍA-ESCUDERO MÁRQUEZ, P. (1998: 427). 
con la Ley 9/2017, de 8 de noviembre, de Contratos del Sector Público, por la que se transponen al ordenamiento jurídico español las Directivas del Parlamento Europeo y del Consejo 2014/23/UE y 2014/24/UE, de 26 de febrero de 2014².

A mayor abundamiento de lo anterior, no podemos olvidar que el sujeto, en sentido amplio, que aprueba tanto esas leyes, a las que las cámaras legislativas están sujetas, como los EE.PP. de las mismas, son los propios parlamentos, por lo que únicamente será objeto de discusión u opinión la forma o fuente en la que se exterioriza la norma, puesto que el contenido del texto normativo es el deseado por su autor.

Consecuencia de todo cuanto antecede, podemos señalar que la Función Pública parlamentaria autonómica, al igual que sucede con las Cortes Generales, no se ha caracterizado por su innovación, pues pese a la reserva estatutaria que realiza la Constitución para el caso del EPCG, o algunos EE.AA. para los EE.PP. de sus cámaras legislativas, los mismos se han limitado prácticamente a reproducir la normativa en vigor para los funcionarios de la Administración pública, cuestiones que son fácilmente observables en materias de clasificación de los funcionarios parlamentarios en los diferentes cuerpos o grupos, sus retribuciones y promoción profesional, entendiendo que los mismos únicamente están sujetos a aquellos preceptos vinculantes establecidos por la Constitución y algunos EE.AA. para sus respectivos EE.PP.

\section{Reserva constitucional. Del Estatuto del Personal de las Cortes Generales}

Las constituciones, con la finalidad de evitar una injerencia normativa ajena a los poderes legislativos (al igual que hacen los EE.AA. respecto a sus parlamentos autonómicos, por mimetismo), suelen establecer una reserva parlamentaria normativa, referida al reglamento de funcionamiento, el reglamento parlamentario ${ }^{13}$.

No obstante, respecto a las normas reguladoras del personal del Poder Legislativo, a diferencia de lo que acontece respecto a los reglamentos de las cámaras, no es normal que las constituciones contemplen expresamente estas competencias. ${ }^{14}$

12 La Ley 9/2017, de 8 de noviembre, de Contratos del Sector Público, por la que se transponen al ordenamiento jurídico español las Directivas del Parlamento Europeo y del Consejo 2014/23/UE y 2014/24/UE, de 26 de febrero de 2014, establece, en la Disposición adicional cuadragésima cuarta, bajo la rúbrica "Régimen de contratación de los órganos constitucionales del Estado y de los órganos legislativos y de control autonómicos" que, el Congreso de los Diputados, Senado, así como las asambleas legislativas de las CC.AA., entre otros órganos constitucionales, deberán ajustar su contratación a las normas establecidas en dicha ley para las Administraciones Públicas.

13 Véanse los arts. 67, 79, 80, 88, 89 y $111 \mathrm{CE}$, que coinciden grosso modo con los procedimientos parlamentarios.

14 MARTÍNEZ LÓPEZ-MUÑIZ, J.L., "Consideraciones sobre el Estatuto del personal de las Cortes Generales: reserva legal y administración parlamentaria”, en I fornadas de Derecho Parlamentario, vol. 
En contraste con ello, la Constitución de 1978, respecto a la reserva normativa que realiza a favor del autogobierno de las Cortes Generales, abarca no solo el reglamento parlamentario, sino también el estatuto del persona ${ }^{15}$ que presta sus servicios en la cámara, posibilitando, en este último supuesto, de este modo, una autoorganización independiente de los esquemas organizativos funcionariales propios del Poder Ejecutivo, y que a la vez, avalados por la autonomía parlamentaria de que disfruta el parlamento, en virtud de la división de poderes, permite una mejor adecuación de organización, tanto de procedimientos como de organización de los medios, a las funciones que tienen atribuidas.

En definitiva, se está otorgando al parlamento una esfera de decisión propia para el desenvolvimiento de las tareas necesarias, al objeto de dar el debido cumplimiento a las funciones atribuidas, sin injerencias indebidas. En tal sentido, el ATC 52/1994, de 16 de febrero de 1994, señala que "el principio de autonomía parlamentaria, constitucional y, en este caso, estatutariamente garantizado, dota a la asamblea legislativa de una esfera de decisión propia [... $]^{\$ 16}$.

Sensu contrario, y consecuentemente con lo anterior, las actividades del Poder Legislativo estarían tutorizadas por sujetos ajenos a las mismas, obteniendo como resultado unas competencias mermadas en todas las facetas (constitucional, política y jurídica), pudiendo ser las mismas, incluso, manipuladas, desde un enfoque jurídico-administrativo y fáctico, conduciendo a fines constitucionales y políticos diferentes de los que primigeniamente hubieran podido resultar.

De este modo, el art. $72 \mathrm{CE}$, en su párrafo primero in initio, establece que "Las cámaras establecen sus propios reglamentos, aprueban autónomamente sus presupuestos y, de común acuerdo, regulan el Estatuto del Personal de las Cortes Generales [...]”.

No es necesario mayor profundidad en lo aquí expuesto respecto a la reserva constitucional en cuanto a la facultad normativa de las Cortes Generales para la elaboración del EPGG, siendo únicamente necesario destacar el papel fundamental que tienen los Poderes Legislativos en la autoregulación de su propio personal, constituyendo el Derecho propio del parlamento un subordenamiento jurídico o, como nosotros preferimos llamar, un ordenamiento jurídico derivado.

Guestión diferente a la expuesta es que dicha reserva constituya en sí misma una reserva de ley formal. En tal sentido, MARTÍNEZ LÓPEZ-MUÑIZ afirma

II. Madrid, Congreso de los Diputados, 1984, p. 670.

15 Véase el art. 72.1 CE referido al EPCG.

16 En el mismo sentido, los AATC 659/1987, de 27 de mayo de 1987, 515/2005, de 19 de diciembre de 2005, 260/2008, de 28 de julio de 2008, 261/2008, de 28 de julio de 2008, 262/2008, de 28 de julio de 2008 y 193/2010, de 1 de diciembre de 2010 en el que dotan de una esfera de decisión propia tanto a asambleas legislativas como a sus órganos parlamentarios. 
que "el artículo 72.1 de la Constitución, constituye, en efecto, una reserva de ley formal de la materia correspondiente [... $]^{\prime, 17}$. Es esta, evidentemente, una cuestión distinta, es decir, si el EPGG constituye una norma con rango de ley, que en este epígrafe no vamos a abordar, sin perjuicio de la jurisprudencia constitucional y del Tribunal Supremo en tal sentido ${ }^{18}$, puesto que lo que aquí nos interesa destacar respecto al EPCG es la reserva constitucional que establece nuestra Norma normarun a favor de ambas cámaras (de común acuerdo).

No obstante, hay que entender al autor citado al hablar de reserva legal a favor de las cámaras en lo relativo al EPCG porque hace un paralelismo al decir que la reserva legal es una técnica que tendrá su utilidad para establecer los límites entre la ley formal y el reglamento, es decir, entre el "Poder Legislativo y Administración pública" y, en el caso concreto que nos ocupa, entre "el Poder Legislativo y la Administración parlamentaria"

\section{Reserva Estatutaria. Del estatuto del personal de las asambleas legislativas de las GG.AA.}

A diferencia de la reserva que el art. 72 CE establece para las Cortes Generales, la Carta Magna no realiza ninguna reserva a favor de las asambleas legislativas de las CG.AA., ni prescribe, ni encarga que se lleve a cabo en ulteriores normas. Cuestión lógica si atendemos a lo dispuesto en el art. 147 CE en relación con el art. $152 \mathrm{CE}$. El primero establece que "dentro de los términos de la presente Constitución, los estatutos serán la norma institucional básica de cada comunidad autónoma y el Estado los reconocerá y amparará como parte integrante de su ordenamiento jurídico" y, en su párrafo segundo, que los EE.AA. deberán contener, entre otras, la organización y sede de las instituciones autónomas propias.

Respecto al segundo de los artículos citados, en lo que se refiere a las asambleas legislativas, y únicamente para los estatutos aprobados por el procedimiento a que se refiere el art. $151 \mathrm{CE}$, las mismas serán elegidas "por sufragio universal, con arreglo a un

17 MARTÍNEZ LÓPEZ-MUÑIZ, J.L. (1984: 679).

18 El EPCG es considerado con rango de ley por el Tribunal Constitucional, en STC 139/1988, de 8 de julio, FJ $2^{\circ}$ y STC 183/2012, de 17 de octubre, FJ $5^{\circ}$. En el mismo sentido, por el Tribunal Supremo, STS de 20 de enero de 1987, FJ $3^{\circ}$ y $4^{\circ}$ (RJ 1987 317 ), y de 10 de octubre de 1989, FJ $3^{\circ}$ (RJ 1989 66857).

19 Insistimos en nuestra discrepancia con MARTÍNEZ LÓPEZ-MUÑIZ porque, precisamente, el EPCG es aprobado por un órgano rector, propio de la Administración parlamentaria, y no por un órgano con competencia legislativa. Si bien es el propio autor, pese a la afirmación de la reserva legal como distinción entre Administración parlamentaria y Poder Legislativo, el que en páginas siguientes establece claramente que las Mesas, en sentido estricto, no tienen funciones normativas legislativas, únicamente funciones normativas reglamentarias y atribuyendo la competencia exclusiva para la aprobación del EPCG al Poder Legislativo, concretamente a las cámaras, no pudiendo ser dictado por la Administración parlamentaria, extremo este último en el que estamos plenamente de acuerdo. MARTíNEZ LÓPEZ-MUÑIZ, J.L. (1984: 680). 
sistema de representación proporcional que asegure, además, la representación de las diversas zonas del territorio".

En consecuencia, de la lectura de ambos preceptos se deduce que serán los EE.AA. de las CG.AA., como norma institucional básica de cada comunidad, los que definirán la organización de sus instituciones, estableciendo el art. 151 CE un requisito que deberá cumplir cada asamblea legislativa. Por tanto, nada se opone para que dichos estatutos puedan establecer una reserva parlamentaria que posibilite una autoorganización independiente de la organización propia del Poder Ejecutivo.

Cuestión controvertida jurídicamente sería plantearnos si dicha reserva parlamentaria, en cuya esfera de acción no podría realizar injerencia alguna el Poder Ejecutivo, fuera realizada en otro nivel distinto del estatutario; por ejemplo, mediante ley ordinaria de la propia asamblea legislativa. En esta hipótesis ¿podría entenderse realizada la reserva porque así lo establece una ley autonómica? O, por el contrario, ¿sería necesario que la reserva fuera contemplada por el Estatuto de Autonomía, pues en caso contrario no se consideraría reserva parlamentaria, ya que, al ser objeto de la organización de sus instituciones de autogobierno, debe ser contemplada, en su caso, por la ley orgánica que aprueba el Estatuto como norma institucional básica? Cuestión esta que es abordada más adelante, pues como veremos, es fundamental que tal reserva esté recogida en los EE.AA. de las diferentes CC.AA., al objeto de la determinación de sus respectivos rangos jurídicos como norma legal.

\section{LA RESERVA DEL ESTATUTO DEL PERSONAL COMO COM- PETENCIA EXCLUSIVA Y ESPECÍFICA DE LOS PARLAMEN- TOS AUTONÓMICOS}

La diferencia existente entre leyes autonómicas y leyes estatales, como adelantábamos al hablar de la "fuerza de ley" de las leyes autonómicas, es respecto al contenido de las mismas, es decir, la capacidad de innovación normativa que cada tipo de ley ostenta y que, a su vez, vendrá determinada por lo dispuesto en el bloque de constitucionalidad.

A mayor concreción de lo anterior, serán los cuerpos de legisladores, estatal y autonómicos, de cada una de las CG.AA., los que determinen la innovación normativa que sus leyes autonómicas puedan abordar, pudiendo establecer, de este modo, los EE.PP. como tipos normativos con competencias específicas en sus respectivos EE.AA.

Entendemos que el elemento basilar de la consideración de los EE.PP. como norma legal es su legitimación por los respectivos EE.AA., es decir, el amparo de la norma que es básica para la organización de sus CG.AA. 


\section{Competencia establecida en el Estatuto de Autonomía respectivo}

En dicha línea, y asumiendo los EE.PP. como competencia asumida por los parlamentos autonómicos, estos serán considerados como leyes autonómicas, pero revestidos (al igual que el resto de leyes autonómicas) de un concepto material de ley, pues se requiere, además del aspecto formal, que la materia (competencia para elaborar y aprobar el Estatuto del personal) se incluya como competencia asumida por las respectivas CA.AA. ${ }^{20}$

Respecto a la primariedad de los EE.PP. de las cámaras parlamentarias, se exige que haya una conexión o vinculación directa con el Estatuto de Autonomía respectivo (sin perjuicio, además, de que los citados EE.PP. de las asambleas legislativas sean aprobados por un órgano parlamentario con competencia legislativa). Por tanto, observamos como primariedad y reserva son aspectos relacionados que se constituyen como presupuestos mutuos.

En tal sentido lo expresa el reiterado anteriormente art. 147.1 CE, al establecer que "los Estatutos serán la norma institucional básica de cada comunidad autónoma”, y de acuerdo con el mismo, la jurisprudencia constitucional, cuando establece la vinculación del Estatuto de Régimen y Gobierno Interior del Parlamento de Navarra, respecto a la LORAFNA (ATS de 10 de octubre de 1989) ${ }^{21}$. O, en el caso de la STC 183/2012, de 17 de octubre ${ }^{22}$, en la que se examinan las Normas de Gobierno Interior del Parlamento de Canarias, en relación a la reserva que pueda hacer el Estatuto de Autonomía de Canarias, también con carácter negativo, de modo análogo, al ATS anterior. Anteriormente, la STG 139/1988, de 8 de julio, consideró norma primaria el EPCG, en virtud de ser una norma directamente vinculada a la Constitución.

20 PÉREZ ROYO caracteriza las leyes autonómicas, además del aspecto formal, del aspecto material, PÉREZ ROYO, J., Las fuentes del Derecho. $2^{\text {a }}$ ed., Madrid, Tecnos, 1985, p.p. 151-152.

En el mismo sentido, ARÉVALO GUTIÉRREZ dice que " [...] la materia disciplinada se enmarque dentro de los títulos competenciales asumidos por la comunidad, es decir, que exista en el Estatuto de Autonomía un apoderamiento concreto [...]", ARÉVALO GUTIÉRREZ, A., "Las leyes de la Asamblea de Madrid", en Asamblea: revista parlamentaria de la Asamblea de Madrid, núm. 1 (1999), p. 153.

21 Dicho autor niega el carácter legal de la norma pues “[...] el Estatuto de Régimen y Gobierno Interior del Parlamento de Navarra no tiene punto de conexión con la LORAFNA, sino que deriva del Reglamento del Parlamento de Navarra (arts. 66, 67.1 y Disposición Adicional Cuarta) [...] ".

22 "[...] podemos ya descartar que las Normas de Gobierno Interior y, por tanto, la Disposición Transitoria Primera, impugnada, en esta cuestión de inconstitucionalidad, tengan fuerza de Ley. No existiendo una reserva en el Estatuto de Autonomía de Canarias a favor del estatuto del personal del Parlamento, no puede predicarse de las Normas de Gobierno Interior su carácter primario o directamente derivado del Estatuto de Autonomía, por lo que carecen de la condición de norma con fuerza y valor de ley y, por tanto, del carácter de «acto con fuerza de ley» [...]". 
Efectivamente, los EE.AA. cumplen unas funciones de complemento constitucional, indicando de forma genérica las características que deben reunir las leyes autonómicas, los órganos de producción, los procedimientos a tales efectos, los ámbitos materiales, el tipo de competencia (legislativa, de ejecución, compartida...) y de forma específica, en su caso, la materia reservada a los EE.PP.

Consecuencia de las previsiones establecidas por los diferentes EE.AA. a los efectos indicados de los EE.PP., así como en virtud de la jurisprudencia del Tribunal Constitucional en las sentencias y autos del mismo, es evidente que estos EE.AA. deben recoger dicha materia en el contenido de sus preceptos.

En tal sentido, lo que se está constituyendo es una competencia específica a favor de la comunidad autónoma en cuestión. Pero tal competencia, la elaboración y aprobación de un estatuto del personal por y para la cámara legislativa de la comunidad autónoma, no es una competencia genérica atribuida a cualquier órgano de esa comunidad, sino que es una competencia exclusiva y específica atribuida a su órgano legislativo.

Tal competencia es perfectamente asumible por las diferentes CG.AA., si estas así lo desean, ya que el art. 149.1.18 ${ }^{\mathrm{a}} \mathrm{CE}$ nada establece en relación a la misma como competencia exclusiva a favor del Estado en materia de Función Pública, por lo que, en virtud de lo establecido en el art. 149.3 CE, "las materias no atribuidas expresamente al Estado por esta Constitución podrán corresponder a las comunidades autónomas, en virtud de sus respectivos Estatutos".

Estaríamos, por tanto, ante una competencia exclusiva y específica a favor de uno de los órganos que forma parte esencial de la organización autonómica, en virtud de lo dispuesto en el art. 147.1. c) y d) CE, de conformidad con el art. 152.1 CE y de acuerdo con el precitado art. 149.1.18 ${ }^{\mathrm{a}} \mathrm{CE}$.

Consecuentemente con lo anterior, las CG.AA. ejercen en tales casos unas funciones competenciales de acuerdo con la reserva estatutaria, en su caso, que el Estatuto de Autonomía ha establecido, ejecutando, por tanto, la reserva competencial exclusiva y específica de elaboración y aprobación legislativa a favor, específicamente, del Poder Legislativo autonómico.

El caso opuesto lo constituye aquel supuesto en que dicha competencia no venga recogida en los EE.AA., por lo que en virtud de lo dispuesto en el art. 149.3 CE, "las competencias sobre las materias que no se hayan asumido por los Estatutos de Autonomía corresponderán al Estado, cuyas normas prevalecerán, en caso de conflicto, sobre las de las comunidades autónomas en todo lo que no esté atribuido a la exclusiva competencia de estas".

En este supuesto, no habiendo hecho uso de esta facultad competencial por parte de las CG.AA., y en su caso específico por sus órganos legislativos, tales com- 
petencias serán asumidas por el Estado, quien, al amparo del art. 149.1.18 a CE, establecerá "las bases del régimen jurídico [...] y del régimen estatutario de sus funcionarios [...]". En dicho caso, los EE.PP. que aprueben las cámaras parlamentarias de las CC.AA. están condicionados a esas normas básicas, cuestión que no debemos confundir en absoluto con la posibilidad o no de aplicación del EBEP a los funcionarios de los parlamentos correspondientes.

\section{Competencia establecida fuera del Estatuto de Autonomía respectivo}

No siendo lo habitual, no obstante, existiría también la posibilidad de que la función de elaboración y aprobación de los EE.PP. por las cámaras parlamentarias de las CG.AA. puedan encontrar su reserva competencial en otras normas legales diferentes a sus respectivos EE.AA. Son aquellas otras normas interpuestas que forman parte del bloque de constitucionalidad, como las leyes del art. $150 \mathrm{CE} \mathrm{u}$ otras leyes competenciales.

Ello tiene su fundamento en que, como sabemos, el contenido del art. 149.1 CE está reservado a la competencia exclusiva estatal, por lo que dichas competencias no podrán ser objeto de regulación estatutaria, en tanto que dejarían de ser materia regulable por el Estado, para ser una regulación alterable mediante la conformidad de la comunidad autónoma correspondiente. En otras palabras, deben continuar en exclusiva bajo el Poder Legislativo del Estado, con la excepción de que las Cortes Generales autoricen su sometimiento a tratados o acuerdos internacionales, conforme a lo dispuesto en la propia Constitución sobre las relaciones internacionales.

Es decir, la capacidad de innovación normativa de los órganos legislativos autonómicos, con inclusión de los EE.PP., se debe básicamente a la Constitución y a los EE.AA., si bien de forma complementaria, e incluso podríamos denominar residual, en el caso de los EE.PP., podríamos pensar que tiene cabida el uso de otros tipos normativos como leyes marco, leyes orgánicas de transferencia u otras leyes competenciales.

En definitiva, estas últimas no serían más que "anexos" a las normas estatutarias, pues lo que hacen es complementar la regulación que realizan los respectivos EE.AA.

Por tanto, a través de estas normas citadas, se podría establecer el marco a través del cual proyectar el estatuto del personal de la asamblea parlamentaria. No obstante, queremos incidir en que sería bastante atípica esta técnica legislativa para contemplar esta competencia autonómica, no habiendo actualmente ningún caso de asambleas parlamentarias cuyos EE.PP. hayan sido contemplados mediante este sistema. 
Si bien es cierto que, cuando el art. 150.2 CE establece que "el Estado podrá transferir o delegar en las comunidades autónomas, mediante ley orgánica, facultades correspondientes a materia de titularidad estatal que por su propia naturaleza sean susceptibles de transferencia o delegación", se está refiriendo a aquellas materias que, por razón de la materia, no son objeto de competencia autonómica, en el sentido de que aparezcan recogidas como tales en sus respectivos EE.AA., al constituir las mismas "materias intramuros" del art. 149.1 CE. Ello no es óbice, en principio, para que estas competencias en materias legislativas, objeto de los EE.PP., puedan ser transferidas mediante estos instrumentos normativos propios del art. $150 \mathrm{CE}$ en aquellos casos en que, naturalmente las CC.AA. no asuman mediante sus EE.AA. dichas competencias y no realicen una modificación de los mismos, al objeto de que el producto normativo elaborado por sus asambleas legislativas de regulación de su personal, EE.PP., puedan tener rango jerárquico y fuerza de ley.

Resta por añadir, en definitiva, que es una cuestión que en la práctica está aún por explorar, no existiendo jurídica ni políticamente impedimento alguno para que estos EE.PP. que aprueban las asambleas parlamentarias de las CG.AA., y que no son contemplados por sus respectivos EE.AA., tengan la atribución normativa competencial en virtud de una ley orgánica aprobada por las Cortes Generales, pero diferente a la ley orgánica que aprueba sus EE.AA.

Por otra parte, dichas competencias a favor de los parlamentos autonómicos, en relación a los EE.PP., tendrán como limitación, como es obvio, el marco descrito en la propia ley orgánica que otorga la susodicha competencia y que, como estamos exponiendo, es ajena al contenido del Estatuto de Autonomía.

Respecto al instrumento normativo utilizado, se deviene en fundamental, pues si esa competencia para dotarse de un estatuto del personal, que se articula como "competencia exclusiva de la asamblea legislativa" estuviera atribuida a través de su Estatuto de Autonomía, sería necesario para su modificación un pacto entre las Cortes Generales y la asamblea legislativa en cuestión. Pero si el instrumento vehicular es otra ley orgánica diferente a su Estatuto de Autonomía, es decir, es una ley orgánica del art. 150.2 CE, se está dejando en poder del Estado la modificación o revocación de la transferencia o delegación de la citada competencia.

No obstante lo anterior, si bien, como hemos indicado no hay obstáculo jurídico y/o parlamentario para que tal circunstancia fuera permitida, no deja de resultar extraño que fuera una ley orgánica no aprobatoria de un Estatuto de Autonomía la que otorgara las competencias a una o varias CC.AA. para que dichos EE.PP. puedan ser productos de esta atribución legislativa a favor de sus órganos legislativos que conforman las propias instituciones de las CG.AA., pues estas CG.AA. no son las que asumirían las competencias enunciadas, tal como prevé el art. 147.2.d) CE. 
A pesar de lo expuesto en este subepígrafe en relación con las competencias que las CC.AA. pueden asumir en materia normativa de Función Pública parlamentaria, al objeto de que puedan elaborar por sus parlamentos autonómicos sus respectivos EE.PP. con un rango determinado, creemos que ello no aporta solución alguna a la consecución de dicho rango jurídico de dichos estatutos.

Si bien las leyes orgánicas previstas en el art. 150.2 CE tienen como finalidad transferir o delegar en las CG.AA. facultades correspondientes a materia de titularidad estatal "que, por su propia naturaleza, sean susceptibles de transferencia o delegación", y es obvio que la elaboración y aprobación de los respectivos EE.PP. por las asambleas legislativas de las CG.AA. se encontrarían en el supuesto indicado, no aportaría a los efectos de rango de estos EE.PP. lo que estas normas requieren, ya que, como establece la jurisprudencia constitucional (varias veces citada), para que se pueda predicar de las mismas el atributo de primariedad, es necesario que estén vinculadas directamente a sus respectivos EE.AA., de los cuales deben derivar directamente.

En otras palabras, las leyes orgánicas de transferencia o delegación de competencias del art. 150.2 CE pueden otorgar las competencias específicas a los parlamentos autonómicos para que estos aprueben sus EE.PP., si bien la facultad para aprobar los EE.PP. es una función intrínseca que se desprende de la propia autonomía parlamentaria y dichas leyes orgánicas podrán atribuir el carácter de rango legal a los mismos y, por tanto, podrán regular aquellas cuestiones para las que se requiera una norma con rango legal, pero la actual jurisprudencia del Tribunal Constitucional y Tribunal Supremo exige, además, que dichos EE.PP. sean normas primarias, y para ello deben derivar de su Estatuto de Autonomía respectivo, no pareciéndonos que dichas leyes del art. 150.2 CE sean el tipo normativo apropiado para ello, ya que claramente el art. 147.2 c) y d) CE establece las leyes orgánicas que aprueban el Estatuto de Autonomía de las diversas CG.AA. como aquellas que deban contener la organización de las instituciones autónomas propias.

Por otra parte, no aportaría nada nuevo el hecho de que una ley orgánica del art. 150.2 CE pudiera atribuir el rango legal a los EE.PP., pues realmente estos podrán remitirse, en aquellos aspectos necesarios en que sea fundamental el rango jerárquico de la norma, a aquellas disposiciones que tengan rango legal.

Tendríamos aquí un caso en el que la jurisprudencia no se ha pronunciado, por lo que nos movemos en este sentido sobre meras hipótesis, ya que ni ha habido ley orgánica del art. 150.2 CE que haya otorgado tales competencias, al objeto de que los EE.PP. aprobados por las cámaras parlamentarias ostenten la condición de rango legal, ni mucho menos el Tribunal Constitucional ha tenido ocasión de interpretar si ello constituiría un valor sustitutivo de la ley orgánica que aprueba el Estatuto de Autonomía. 
Tal como recuerda MARTÍNEZ LÓPEZ-MUÑIZZ23, este tipo de leyes (al amparo del art. 150.2 CE) "son leyes unilaterales del Estado, sin que puedan incorporarse al contenido de los Estatutos de Autonomía".

A todo ello debemos añadir que, tal como prevé el art. 150.2 CE, dichas leyes preverán las formas de control que se reserve el Estado, lo que en ningún caso es admisible en relación con los parlamentos autonómicos, a los efectos de la elaboración y aprobación de sus respectivos EE.PP.

Por último, si no tiene cabida que el Estado ejerza una tutela o control sobre un parlamento autonómico respecto a su potestad autonormativa y autoorganizativa, plasmada en sus normas internas como constituyen sus EE.PP., tampoco tiene sentido que sea una competencia que igual se pueda otorgar a dichas cámaras legislativas (descentralización y/o delegación) en un momento determinado y, en otro momento distinto, pudieran ser recentralizadas o revocadas, también unilateralmente; cuestiones totalmente diferentes al régimen de autonomía, que conlleva que los Estatutos de esas CG.AA. comporten la transferencia y asunción de sus propias competencias.

\section{Conclusión}

En definitiva, desde nuestro punto de vista, el sistema de distribución competencial se convierte en un prius en la fijación del tipo normativo de los EE.PP., de tal manera que será conditio sine qua non para que los mismos puedan tener el rango y fuerza de ley, siempre y cuando cumplan otros requisitos. En virtud de ello, afirmamos que ello será condición necesaria, pero no suficiente, para que los EE.PP. ostenten tal condición de norma legal.

En otro orden de cosas, podemos pensar que la posible asunción de la competencia en materia de Función Pública por las asambleas legislativas de las CG.AA., como competencia exclusiva y específica de tales órganos legislativos, conlleva lo que posiblemente fue un "olvido" por parte del constituyente en el momento de fijar las competencias exclusivas estatales del art. 149.1.18 $\mathrm{CE}$, al establecer únicamente las relativas a "las bases del régimen jurídico de las administraciones públicas y del régimen estatu-

23 MARTÍNEZ LÓPEZ-MUÑIZ, J. L., "Límites constitucionales generales del contenido de las reformas estatutarias", en Revista furídica de Castilla y León, núm. extraordinario (2004), p. 108.

Consecuentemente, se diferencian de las leyes orgánicas que aprueban los Estatutos de Autonomía, pues en caso contrario carecería de cualquier justificación la previsión diferenciada que realiza el art. 150.2 CE. En tal sentido lo señala el autor.

Ya no hablamos de la voluntad de las CC.AA. al aprobar sus propios EE.AA., si bien de forma paccionada con la voluntad del Estado, pues aquellas leyes orgánicas (las del art. 150.2 CE) son por voluntad unilateral estatal, como modalidades de transferencia de competencias que, por vía principal, la descentralización, o por vía de sustitución, la delegación, se determinan por el Estado. 
tario de sus funcionarios", no contemplando en ningún momento como competencia la regulación de los funcionarios públicos de las cámaras parlamentarias autonómicas.

En tal sentido, el legislador autonómico puede innovar el ordenamiento jurídico cuya competencia ostenta, de forma plena a la realizada por el legislador estatal, en materia de Función Pública parlamentaria, en la elaboración y aprobación del estatuto del personal, de conformidad con los preceptos constitucionales que les son aplicables. Y, en dicho plano teórico, los parlamentos autonómicos podrán proceder a realizar regulaciones legislativas propias totalmente divergentes a las estatales; cuestión diferente es el plano práctico, ya que las cámaras legislativas actúan en sus regulaciones normativas de modo mimético al resto de las regulaciones jurídicas en materia de Función Pública.

\section{CONCLUSIONES: REFLEXIÓN EN TORNO A LAS CITADAS RESERVAS Y SU RELAGIÓN GON LA AUTONOMÍA PARLA- MENTARIA}

Las reservas competenciales que pueden realizar los diversos EE.AA. no determinan, por sí solas, el rango de la norma jurídica (legal o reglamentario) de los EE.PP. Por ello, podemos decir que es un prius, es decir, es condición necesaria pero no suficiente para que el estatuto del personal tenga rango legal, ya que, además, han de cumplirse determinadas condiciones formales. En tal sentido, se exige por la jurisprudencia constitucional una reserva estatutaria, al objeto de que exista una vinculación entre el estatuto del personal y el Estatuto de Autonomía o, en otras palabras, una incardinación de aquel en este último. (STG 139/1988, de 8 de julio y STC 183/2012, de 7 de octubre).

En otro orden de cosas, las normas de competencia son de aplicación preferente respecto al principio de jerarquía, ya que las reglas de rango únicamente se pueden aplicar respecto de normas jurídicas que han sido producidas de acuerdo con el principio de competencia. En tal sentido, serán aplicables tanto una ley general como una norma parlamentaria interior, si ambas tienen competencias en el objeto de que se trate, si así lo ha establecido la Constitución y, en su caso, los EE.AA. respectivos, respecto a la organización, procedimiento o cualquier otro aspecto de la regulación de las asambleas legislativas. ${ }^{24}$ En definitiva, únicamente en los supuestos en los cua-

24 Ejemplos de lo expuesto pueden constituir diversas leyes de transparencia, al coincidir la Ley 19/2013, de 9 de diciembre, de Transparencia, con las leyes autonómicas en sus respectivos ámbitos, y ambas a su vez, nacional y autonómica, con la norma interna de la asamblea parlamentaria en dicha materia. O bien aquellos casos en los que la competencia de la regulación en general corresponde al parlamento, pero en determinados supuestos se atribuye al legislador general, como sucede con la relación de comisiones parlamentaria, que son objeto de regulación por el reglamento parlamentario, si bien también pueden ser creadas en virtud de una ley. 
les la regulación es debida a una competencia simultánea es donde el conflicto habrá que acudir al criterio de jerarquía normativa.

Por ello, es fundamental la reserva que los EE.AA. hacen a favor de sus cámaras, al objeto de que las mismas elaboren y aprueben sus respectivos EE.PP., para que puedan disponer del rango legal y ostenten plena capacidad competencial y rango jerárquico suficiente en orden a establecer la regulación de su propio personal sin necesidad de remisión alguna a otra norma ajena por carecer de dicho rango ${ }^{25}$.

Por otra parte, habrá que tener en consideración que la técnica de reserva material de la regulación del personal en favor de las asambleas legislativas, "determina los limites entre el Parlamento, entre el Poder Legislativo y la Administración parlamentaria [...]”26.

25 Véase a CANO SILVA, R., La función pública de las asambleas parlamentarias de las CC.AA.: Bases para la elaboración de los estatutos del personal, Madrid, Editorial Académica Española, 2018. En esta obra, el autor hace un estudio profundo de las competencias de las asambleas legislativas de las CC.AA., en materia de función pública, en relación con el art. 149.1.7 y $149 \cdot 1 \cdot 18^{\mathrm{a}} \mathrm{CE}$.

26 MARTÍNEZ LÓPEZ-MUÑIZ, J.L. (1984: 679). 


\section{BIBLIOGRAFÍA}

ARÉVALO GUTIÉRREZ, A., "Las leyes de la Asamblea de Madrid". Asamblea: revista parlamentaria de la Asamblea de Madrid, núm. 1 (1999), págs. 147-188.

CANO SILVA, R., "La potestad autonormativa en relación con los estatutos del personal de los parlamentos autonómicos". Revista de Estudios de la Administración Localy Autonómica, núm. 9, (2018), págs. 99-109.

- La función pública de las asambleas parlamentarias de las CC.AA.: Bases para la elaboración de los estatutos del personal. Madrid: Editorial Académica Española, 2018.

GARCÍA-ESCUDERO MÁRQUEZ, P., "Artículo 72.1: autonomía funcional de las cámaras: reglamentaria, presupuestaria y de personal". En: Comentarios a la Constitución Española, Alzaga Villaamil, O., (dir.). Vol. VI. Madrid: Cortes Generales, Edersa, 1998, págs. 389-429.

MARTÍNEZ LÓPEZ-MUÑIZ, J.L., "Consideraciones sobre el Estatuto del personal de las Cortes Generales: reserva legal y administración parlamentaria". En: I Fornadas de Derecho Parlamentario, vol. II. Madrid: Congreso de los Diputados, 1984, págs. 667-685.

- "Límites constitucionales generales del contenido de las reformas estatutarias". Revista Furídica de Castilla y León, núm. extraordinario (2004), págs. 91-120.

MARTÍNEZ-ELIPE, L., "Fuentes del Derecho y del ordenamiento jurídico parlamentario". En: I fornadas de Derecho Parlamentario, vol. II. Madrid: Congreso de los Diputados, 1984, págs. 431-503.

PÉREZ ROYO, J., Las fuentes del Derecho. $2^{\mathrm{a}}$ ed. Madrid: Tecnos, 1985.

PUnSET BLANCO, R., Las Cortes Generales. Madrid: Centro de Estudios Constitucionales, 1983.

- "La posición de los reglamentos parlamentarios en el ordenamiento español". En: Las fuentes del Derecho parlamentario, Da Silva Ochoa, J.G. (coord.). Vitoria-Gasteiz: Parlamento Vasco, 1996, págs. 67-86. 